\title{
СПЕЦИФИКА КАРЬЕРНОГО КОНСТРУИРОВАНИЯ И ВОЗМОЖНОСТИ СОЦИАЛЬНО-ПСИХОЛОГИЧЕСКОГО СОПРОВОЖДЕНИЯ КАРЬЕРНОГО КОНСТРУИРОВАНИЯ МОЛОДЫХ СПЕЦИАЛИСТОВ
}

\section{THE SPECIFICS OF CAREER DESIGN AND THE POSSIBILITY OF SOCIO-PSYCHOLOGICAL SUPPORT FOR THE CAREER DESIGN OF YOUNG SPECIALISTS}

M. Tauseneva S. Gurieva

Summary: The article discusses the specifics of career design and the possibility of socio-psychological support for the career design of young specialists. It is noted that the career development of young specialists is determined by the presence of a certain amount of knowledge, sociopsychological characteristics and professionally significant personal qualities. The importance of social and psychological support for young specialists is considered. Depending on the degree of integrity of career ideas, experience, awareness of career choices and understanding of the career path, the possibilities of social and psychological support of young specialists are presented. It is noted that the possibilities of social and psychological support are determined by the level of formation of career ideas. It was revealed that the directions of work within the framework of social and psychological support of young specialists are implemented at different levels: cognitive; communicative; reflective; motivational; behavioral; personal.

Keywords: career design, young specialists, social and psychological support.

\author{
Таусенева Мария Сергеевна \\ Санкт-Петербургский государственный университет \\ tausenevams@gmail.com \\ Гуриева Светлана Дзахотовна \\ Д.nсх.н., профессор, Санкт-Петербургский \\ государственный университет \\ tausenevams@gmail.com
}

Аннотация: В статье рассматривается специфика карьерного конструирования и возможности социально-психологического сопровождения карьерного конструирования молодых специалистов. Отмечено, что карьерное конструирование молодых специалистов определяется наличием определенного объема знаний, социально-психологическими особенностями и профессионально значимыми личностными качествами. Рассмотрена важность социально-психологического сопровождения молодых специалистов. В зависимости от степени целостности карьерных представлений, опыта, осознанности карьерного выбора и пониманию карьерного пути представлены возможности социально-психологического сопровождения молодых специалистов. Отмечено, что возможности социально-психологического сопровождения определяются уровнем сформированности карьерных представлений. Выявлено, что направления работы в рамках социально-психологического сопровождения молодых специалистов реализуются на разных уровнях: когнитивном; коммуникативном; рефлексивном; мотивационном; поведенческом; личностном.

Ключевые слова: карьерное конструирование, молодые специалисты, социально-психологическое сопровождение.
$\mathrm{B}$ современном обществе наблюдаются противоречия между традиционными взглядами на позицию молодого специалиста как неопытного, недостаточно подготовленного выпускника образовательного учреждения и реальной ситуацией на рынке труда. Более половины выпускников объективно оценивают свое положения как работника, ориентируются при выборе работы не на уровень заработной платы, а на возможности карьерного роста, самореализации [5]. При этом значительную роль играют мотивация, адаптационные способности к новым условиям труда, обучаемость, профессионально значимые личностные качества.

Сфера карьерного конструирования тесто связана с направлениями изучения мотивации профессиональной деятельности в системе управления карье- рой, адаптационных способностях к профессиональной деятельности.

Карьерное конструирование можно рассматривать как одно из направлений управления человеческими ресурсами, включающая мотивацию к управлению карьерой [12; 13], развитие организации при правильном карьерном движении сотрудников [8] мотивы выбора профессии, содержания трудовой деятельности и места работы [4].

По мнению M. Armstrong, выбор карьерного пути основан на установках личности по отношению к содержанию профессии, внутренних ценностях, представлениях о профессии в целом, что является основой приверженности сотрудников в организации и способствует более 
осознанной профессиональной деятельности [9].

В этой связи мотивация профессиональной деятельности является одним из значимых составляющих системы управления карьерой в организации прежде всего молодых специалистов и должна соответствовать ценностям сотрудника, формированию квалифицированного мотивированного персонала [15; 9], [18].

Другая позиция охватывает взаимосвязь карьерного конструирования и адаптационных способностей специалистов. По мнению Schein, Oosthuizen et al., предоставленная сотрудникам возможность видеть результаты адаптации к новым трудовым требованиям, специфике и содержанию работы, позволяет оценить свои способности как профессионала, возможность в получении новых профессиональных навыков и развитии компетенций, а также определить индивидуальную карьерную траекторию [19; 18].

В исследованиях М.О. Латуха, Bauer, KammeyerMueller et al. отмечается, что наиболее важными в выборе продолжения работы в организации является адаптационный период в первые три месяца $[6 ; 11 ; 17]$. В связи с этим на этапе отбора персонала необходимо получать информацию о карьерных предпочтениях, ценностях и внутренних ожиданиях кандидатов, сравнивать их с возможностями самой организации, особенностями существующего кадрового состава, что позволить определить степень возможного закрепления молодого специалиста в компании. Соответственно, важным является прогнозирование результатов адаптации персонала, оценка их профессионального и карьерного развития [10; 14]).

E.H. Schein предложил концепцию «якорей карьеры» [19], которая позволяет определить способности, мотивы и ценности сотрудников, их личностные установки в рамках конструирования карьеры.

Н.В. Волкова, В.А. Чикер рассматривали карьерные ориентации с целью определения профессиональной мотивации в зависимости от сферы деятельности, профессионального статуса и пола респондентов [2;3;7].

В.А. Чикер, Н.В. Васина, М.В. Бучацкая, М.В. Капранова изучали формирование карьерных представлений с точки зрения гендерных различий [1; 7]. В рамках данных исследований выявлено, что карьерное конструирование тесто связано с содержанием профессиональной деятельности, мотивацией, личностными характеристиками, характеризуются устойчивостью и социальной направленностью.

M. Snyder разработал теорию самомониторинга, в основе которой лежит субъектная адаптация к соци- альной и профессиональной среде, проявляющаяся в одобрении создаваемого образа социальной ситуации и гибкости в межличностных и профессиональных коммуникациях [20].

Исходя из вышеизложенного, целесообразно сделать вывод о том, что карьерное конструирование молодых специалистов определяется наличием определенного объема знаний, социально-психологическими особенностями и профессионально значимыми личностными качествами. Соответственно, особую важность приобретает социально-психологическое сопровождение молодых специалистов, которое позволяет:

- выстроить карьерное конструирование на индивидуальном уровне и уровне организации;

- учитывать этапы развития молодого специалиста как сотрудника (этап профессиональной подготовки, адаптации, развития, совершенствования);

- учитывать социально-психологические особенности молодого специалиста (ценности, карьерные ориентации, мотивы, мотивацию, знания и др.);

- использовать разные методы изучения данных характеристик и методы формирования карьерного конструирования.

В зависимости от степени целостности карьерных представлений, опыта, осознанности карьерного выбора и пониманию карьерного пути целесообразно представить возможности социально-психологического сопровождения молодых специалистов (табл.1).

На основе представленных возможностей социально-психологического сопровождения молодых специалистов следует отметить, что направления работы реализуются на разных уровнях:

- когнитивном (комплекс знаний, полученных при обучении в ВУЗе и знаний, специфичных для конкретной организации);

- коммуникативном (взаимодействие с потенциальными и существующими работодателями, с членами коллектива);

- рефлексивном (способность к объективному оцениванию своих способностей и возможностей в профессиональном развитии);

- мотивационном (стремление развиваться профессионально);

- поведенческом (выявление неэффективных моделей поведения при поиске работы, в коллективе);

- личностном (способность к самостоятельному определению своего карьерного пути).

Таким образом, на основе вышеизложенного целесообразно сделать следующие выводы.

1. Специфика и содержание карьерного конструирования имеет особенности на каждом уровне карьерных представлений. На теоретическом 
Таблица 1.

Уровни сформированности карьерных представлений и возможности социально-психологического сопровождения молодых специалистов

\begin{tabular}{|c|c|c|c|}
\hline $\begin{array}{l}\text { Уровни сформированности } \\
\text { карьерных представлений }\end{array}$ & $\begin{array}{l}\text { Характеристика особенностей } \\
\text { карьерного конструирования }\end{array}$ & $\begin{array}{l}\text { Направления социально-психоло- } \\
\text { гического сопровождения }\end{array}$ & $\begin{array}{l}\text { Цель социально-психологического } \\
\text { сопровождения }\end{array}$ \\
\hline Теоретический & $\begin{array}{c}\text { Отсутствие целостности и обрыви- } \\
\text { стость карьерных представлений } \\
\text { Характер описания работы имеет } \\
\text { вид «отчета о проделанной работе» } \\
\text { В большей степени эмоционально- } \\
\text { оценочное отношение к работе } \\
\text { Постоянные сомнения }\end{array}$ & $\begin{array}{c}\text { Беседа } \\
\text { Наблюдение в непосредственной } \\
\text { профессиональной деятельности } \\
\text { Инструктаж } \\
\text { Диагностика личностного и } \\
\text { профессионального развития } \\
\text { Наставничество } \\
\end{array}$ & $\begin{array}{c}\text { Понимание содержания, задач } \\
\text { работы, своей роли в организации, } \\
\text { в коллективе } \\
\text { Определение зон роста } \\
\text { Определение карьерных } \\
\text { ориентаций, мотивации к работе }\end{array}$ \\
\hline Интерпретативный & $\begin{array}{c}\text { Недостаточная целостность } \\
\text { карьерных представлений } \\
\text { Незавершенность } \\
\text { профессиональной ситуации } \\
\text { Неуверенность в своем } \\
\text { карьерном выборе } \\
\text { Недостаточная адаптация } \\
\text { к содержанию и условиям } \\
\text { рабочего процесса }\end{array}$ & $\begin{array}{c}\text { Инструктаж } \\
\text { Проблемные ситуации } \\
\text { Коучинг } \\
\text { Рефлексия } \\
\text { Развитие на рабочем месте } \\
\text { Наставничество }\end{array}$ & $\begin{array}{c}\text { Достижение успешности } \\
\text { Определение критериев } \\
\text { собственной успешности } \\
\text { Определение зон роста } \\
\text { Определение путей карьерного } \\
\text { развития }\end{array}$ \\
\hline Рефлексивный & $\begin{array}{c}\text { Целостность } \\
\text { Развернутость } \\
\text { Конкретное содержание и результат } \\
\text { работы } \\
\text { Осознанная профессиональная } \\
\text { позиция } \\
\text { Эмоционально-оценочное } \\
\text { отношение к работе } \\
\text { Наличие четких критериев } \\
\text { успешности как профессионала } \\
\text { Осознанность своей статусности }\end{array}$ & $\begin{array}{c}\text { Коучинг } \\
\text { Индивидуальный план развития } \\
\text { Ориентация на личностное } \\
\text { развитие }\end{array}$ & $\begin{array}{c}\text { Личностное и профессиональное } \\
\text { развитие } \\
\text { Определение зон роста } \\
\text { Саморазвитие } \\
\text { Определение стратегий и путей } \\
\text { карьерного роста }\end{array}$ \\
\hline
\end{tabular}

уровне у молодого специалиста наблюдается отсутствие целостности образа дальнейшей карьеры, сохраняется эмоционально-оценочное отношение к работе в целом, к профессии, молодой специалист сомневается в карьерном выборе, мотивация во многом зависит от наличия желания работать в данной сфере в целом, оцениваются само содержание и условия работы. На интерпретативном уровне молодой специалист осознает незавершенность профессиональной ситуации, наблюдается неопределенность в выборе профессии, сферы деятельности, организации, сложности в адаптации к содержанию работы. На рефлексивном уровне молодой специалист получил достаточно знаний, опыта для осознанного понимания своей профессиональной позиции, имеет четкое представление о своем карьерному пути, может адекватно определить зоны роста и способы их корректировки для достижения цели.

2. Возможности социально-психологического сопровождения определяются уровнем сформированности карьерных представлений. На теорети- ческом уровне для молодого специалиста важно понять свое предназначение как специалиста, определить свое карьерные устремления, определить пути дальнейшего профессионального развития. Для решения данных задач эффективными направлениями сопровождения будут инструктаж, беседа, консультация, наставничество. На интерпретативном уровне наибольшую эффективность приобретают анализ проблемных ситуаций, коучинг, рефлексия, развитие на рабочем месте, наставничество, направленные на выявление зон роста в профессиональном развитии и их корректировки. На рефлексивном уровне для молодого специалиста важен индивидуальный план личностного и профессионального развития с акцентом на развитие профессионально значимых личностных качеств для карьерного роста.

3. Основными методами работы с молодыми специалистами в содержании социально-психологического сопровождения могут стать собеседование, коучинг, беседа по итогам первой недели работы в компании, составление индивидуального 
плана личностного развития (коммуникативный, личностный, рефлексивный компоненты); наставничество с руководителем на рабочем месте (поведенческий, рефлексивный, мотивационный и коммуникативный компоненты); обучение по продукту / услугам компании, стандартам работы и т.д. (когнитивный, личностный, мотивационный, коммуникативный, рефлексивный компоненты); конструктивная обратная связь по итогам работы (достижения / неудачи, качество работы).

\section{ЛИТЕРАТУРА}

1. Васина Н.В., Бучацкая М.В., Капранова М.В. Психологическое содействие карьерному росту субъекта труда в процессе профессионального становления // Человеческий капитал. - 2014. - № 11(71). - С. 79-81.

2. Волкова Н.В., Чикер В.А. Адаптация персонала в российских организациях: различия профессиональной мотивации и уровня самомониторинга представителей трех поколений (на материале компаний г. Санкт-Петербурга) // Вестник Московского ун-та. Сер. 14. - 2015. - № 4. С. 21-38.

3. Волкова Н.В., Чикер В.А. Особенности карьерной мотивации в контексте теории поколений: результаты эмпирического исследования // Вестник Санкт-Петербургского университета. Менеджмент. - 2016. - №4. - URL: https://cyberleninka.ru/article/n/osobennosti-kariernoy-motivatsii-v-kontekste-teoriipokoleniy-rezultaty-empiricheskogo-issledovaniya (дата обращения: 08.04.2021).

4. Ильин Е.П. Мотивация и мотивы. - СПб.: Питер, 2011. - 248 с.

5. Казанцева Е.Е. Особенности кадровой политики при работе с представителями разных поколений // Управление человеческим потенциалом. - 2014. № 1. - C. 14-20.

6. Латуха М.0. Управление талантливыми сотрудниками: теоретические подходы и опыт российских компаний // Вестник С.-Петерб. ун-та. Сер. Менеджмент. - 2014. - № 4. - С. 46-67.

7. Почебут Л.Г., Гуриева С.Д., Чикер В.А. Прогностическая модель социально-психологических факторов укрепления доверия в организации // Социальная психология и общество. -2018. -Т.9. -№1. -С. 22-42.

8. Тарарухина 0.В., Гуриева С.Д. Развитие методологии изучения межличностных отношений в социальной психологии // Вестник Северо-Осетинского государственного университета имени К.Л. Хетагурова. -2016. -№1. -С. 101-107.

9. Armstrong M. A Handbook of Human Resource Management Practice. - London, Kogan Page, 2006. - 189 p.

10. Ashforth B., Saks A. Organizational Socialization: Making Sense of the Past and Present as a Prologue for the Future // Journal of Vocational Behavior. 1997. -Vol. 51. - Pp. 234-279.

11. Bauer T. Onboarding New Employees: Maximizing Success. - SHRM Foundation, 2010. - URL: http:// www.shrm.org/about/foundation/products/ Documents/0nboarding\%20EPG-\%20FINAL.pdf (дата обращения: 15.03.2021).

12. Clarke M. Understanding and Managing Employability in Changing Career Contexts // Journal of European Industrial Training. - 2008. - Vol. 32. - Pp. 258-284.

13. Cullen L., Christopher T. Career Progression of Female Accountants in the State Public Sector // Australian Accounting Review. - 2012. - Vol. 22 . - Pp. $68-85$.

14. Field R., Coetzer A. The Effects of Organizational Socialization on Individual and Organizational Outcomes: A Review of the Literature and Directions for Future Research // Labour, Employment and Work in New Zealand. Proceedings of 2008 Labour, Empoyment and Work Conference in New Zealand. - 2008. - Pp. 524-533. URL: https://ojs.victoria.ac.nz/LEW/article/view/1673 (дата обращения: 01.04.2021).

15. Igbaria M., Kassicieh S.K., Silver M. Career Orientations and Career Success among Research, and Development and Engineering Professionals // Journal of Engineering and Technology Management. - 1999. - Vol. 16. - Pp. $29-54$.

16. Gubler M., Biemann T., Tschopp, C., Grote, G. How Career Anchors Differentiate Managerial Career Trajectories: A Sequence Analysis Perspective // Journal of Career Development. - 2015. - Vol. 42. - Pp. 412-430.

17. Kammeyer-Mueller J., Wanberg C., Rubenstein A., SongtZ. Support, Undermining, and Newcomer Socialization: Fitting during the First 90 Days // Academy of Management Journal. - 2013. - Vol. 56. - Pp. 1104-1124.

18. Oosthuizen R.M., Coetzee M., Mntonintshi F. Investigating the Relationship between Employees' Career Anchors and Their Psychosocial Employability Attributes in a Financial Company: Original Research // SA Journal of Human Resource Management. - 2014. - Vol. 12. - Pp. 1-10.

19. Schein E.H. Career Anchors Revisited: Implications for Career Development in the 21st Century // The Academy of Management Executive. - 1996. - Vol. 10. - Pp. 80-88.

20. Snyder M. Self-Monitoring of Expressive Behavior // Journal of Personality and Social Psychology. - 1974. - Vol 30. - Pp. 526-537.

( Таусенева Мария Сергеевна (tausenevams@gmail.com), Гуриева Светлана Дзахотовна (tausenevams@gmail.com).

Журнал «Современная наука: актуальные проблемы теории и практики» 